\title{
Covid-19: Public health must be "at the core" of global recovery plans, say doctors
}

\section{Gareth lacobucci}

The BMJ

Global health leaders have urged governments to put public health "at the core" of economic recovery from covid- 19 .

In a joint letter ${ }^{1}$ to all G20 heads of state, organisations representing over 40 million doctors, nurses, and other health professionals say national economic stimulus packages should be designed and approved by medical and scientific leaders, to ensure that "short and long term public health repercussions" are prioritised in policy making.

The letter, coordinated by the Global Climate and Health Alliance, the Every Breath Matters campaign, and the World Health Organisation, says that the covid- 19 pandemic has exposed the vulnerability of communities when health, food security, and freedom to work are interrupted by "a common threat."

"We have witnessed death, disease, and mental distress at levels not seen for decades," it says. "These effects could have been partially mitigated, or possibly even prevented, by adequate investments in pandemic preparedness, public health, and environmental stewardship. We must learn from these mistakes and come back stronger, healthier, and more resilient."

The letter argues for a science based approach to recovery which must include decisions to reduce both air pollution and greenhouse gas emissions.

"The enormous investments your governments will make over the coming months in key sectors like healthcare, transport, energy, and agriculture must have health protection and promotion embedded at their core," it says.

"We must use smarter incentives and disincentives in the service of a healthier, more resilient society. If governments were to make major reforms to current fossil fuel subsidies, shifting the majority towards the production of clean renewable energy, our air would be cleaner and climate emissions massively reduced, powering an economic recovery that would spur global gains of almost \$100tn (£820bn; €917bn) between now and 2050."

Signatories of the letter include the World Medical Association, the World Organisation of Family Doctors, the World Federation of Public Health Associations, and the UK Health Alliance on Climate Change — of which The BMJ is a member. The BMA, the Royal College of Physicians, the Royal College of GPs, the Royal College of Psychiatrists, the Royal College of Paediatrics and Child Health, and the Primary Care Respiratory Society have also signed.

Miguel R Jorge, president of the World Medical Association, said, "We know, now more than ever, that healthy lives depend on a healthy planet. As we walk on the road to recovery, we can't ignore that we need to build a system that will protect us from further damage. That is why it's important that governments take into consideration public health when they are discussing recovery packages."

Jeni Miller, executive director of the Global Climate and Health Alliance, said, "This is not the time to go back to business as usual, it is a time to take bold steps forward to create a future that protects both people and the planet."

Letter to G20 heads of state. https://healthyrecovery.net/letter. Published by the BMJ Publishing Group Limited. For permission to use (where not already granted under a licence) please go to http://group.bmj.com/group/rights-licensing/ permissions 